\title{
Isolation, characterization and immunomodulatory-associated gene transcription of Wharton's jelly-derived multipotent mesenchymal stromal cells at different trimesters of cow pregnancy
}

\author{
Tereza C. Cardoso ${ }^{1} \cdot$ Lucas H. Okamura $^{1}$ - Jamila C. Baptistella ${ }^{1,2}$. \\ Roberto Gameiro $^{1,3}$ • Helena L. Ferreira ${ }^{4}$ - Márcia Marinho ${ }^{1}$. \\ Eduardo F. Flores 5
}

Received: 11 October 2015 / Accepted: 6 September 2016/Published online: 27 September 2016

(C) Springer-Verlag Berlin Heidelberg 2016

\begin{abstract}
The possibility of isolating bovine mesenchymal multipotent stromal cells (MSCs) from fetal adnexa is an interesting prospect due to the potential use of these cells in biotechnological applications. However, little is known about the properties of these progenitor cells in bovine species. Wharton's jelly (WJ) MSC cells were obtained from the umbilical cord of bovine fetuses at three different stages of pregnancy and divided into groups 1, 2 and 3 according to gestational trimester. Cell morphology, from the three stages of pregnancy, typically appeared fibroblast-like spindle-shaped, presenting the same viability and number. Moreover, the proliferative ability of T-cells in response to a mitogenic stimulus was suppressed when WJMSC cells were added to the culture. Multilineage properties were confirmed by their ability to
\end{abstract}

Tereza C. Cardoso

tcardoso@fmva.unesp.br

1 Laboratory of Animal Virology and Cell Culture College of Veterinary Medicine, UNESP- Sao Paulo State University, Araçatuba, São Paulo 16050-680, Brazil

2 Domestic Animals Anatomy Section, College of Veterinary Medicine, UNESP- Sao Paulo State University, Araçatuba, São Paulo 16050-680, Brazil

3 Domestic Animals Embryology Section, College of Veterinary Medicine, UNESP- Sao Paulo State University, Araçatuba, São Paulo 16050-680, Brazil

4 Department of Veterinary Medicine, FZEA- USP- University of Sao Paulo, Av. Duque de Caxias Norte, 225, Pirassununga, SP 13635-900, Brazil

5 Departament of Preventive Veterinary Medicine, College of Veterinary Medicine, Federal University of Santa Maria, UFSM, Santa Maria, RS 97115-900, Brazil undergo adipogenic, osteogenic/chondrogenic and neurogenic differentiation. Mesenchymal phenotyping, CD105+, CD29+, CD73+ and CD90+ cell markers were detected in all three cell groups, yet these markers were considered more expressed in MSCs of group $2(p<0.005)$. Expression of cytokines IL2, IL6RR, INFAC, INFB1, IFNG, TNF and LTBR were downregulated, whereas $I L 1 F 10$ expression was upregulated in all tested WJMSCs. The present study demonstrated that WJMSCs harvested from the bovine umbilical cord at different gestational stages showed proliferative capacity, immune privilege and stemness potential.

Keywords Stem cells $\cdot$ Umbilical cord · Immunomodulation $\cdot$ Bovine

\section{Introduction}

Wharton's jelly (WJ) is the primitive mucous, connective tissue of the umbilical cord, lying between the amniotic epithelium and umbilical vessels (Troyer and Weiss 2008; Taghizadeh et al. 2011). First described by Thomas Wharton in 1656, this structure is composed mainly of proteoglycans and collagen (Cremonesi et al. 2011; Corrao et al. 2013). In 2006, in order to pursue standardization, the Mesenchymal and Tissue Stem Cell Committee (ISCT) proposed that: mesenchymal cells must be designed as multipotent mesenchymal stromal cells (MSC); be adherent to plastic culture ware; show specific surface antigen expression; and multipotent differentiation potential (Dominici et al. 2008; Calloni et al. 2014; Iacono and Merlo 2015).

The MSC population in WJ of the umbilical cord (UC) present properties that make it of interest (Pham et al. 2016). 
For example, these cells are easy to harvest by non-invasive procedures, provide large number of cells without risk to the donor and can be expanded, genetically manipulated and differentiated in vitro (Troyer and Weiss 2008; Cremonesi et al. 2011; Corrao et al. 2013; Calloni et al. 2014). The immunogenicity of WJMSC has been proposed but is still not clear at present, although immunossupressive effects of bone marrow MSC have been extensively studied and tested in several animal species (Weiss et al. 2008; De Miguel et al. 2012; Mukonoweshuro et al. 2014). Several studies have described WJMSC properties harvested from pregnant women at birth (Prasanna et al. 2010). Nonetheless, WJMSC from bovines (Cardoso et al. 2012) and from buffaloes have been reported only recently (Singh et al. 2013). However, bovine MSCs derived from umbilical cord blood (UCBMSCs), amniotic fluid (AFMSCs) and bone marrow (BMMSCs) have been described (Lu et al. 2011; Raoufi et al. 2011; Corradetti et al. 2013; Cortes et al. 2013). Despite the importance of bovine species as a model for in vitro studies because bovine pregnancy lasts 280 days, as in human beings, there is a lack of information about WJMSCs isolated during cow pregnancy. In contrast to MSCs from different sources, the characterization of bovine MSCs is far from being completely understood, and contradictory information emerges from the literature.

The aim of this study was to isolate and propagate bovine WJMCS cells collected from umbilical cords at three trimesters of pregnancy. Additionally, comparisons were made regarding cell viability, T-cell inhibition, telomerase activity, cell proliferation, phenotype, multipotency and immunomodulatory gene expression. This study highlights a possible potential source of multipotent MSCs and may support their therapeutic and biotechnological use in large animals.

\section{Materials and methods}

\section{Isolation of WJMSC from bovine umbilical cord at different stages of pregnancy}

Bovine UC were harvested at a slaughterhouse from pregnant Nelore cows $(n=18)$. The bovine pregnancy was divided into three trimesters, as done in humans and gestational periods were estimated by measuring the crown rump length of the fetuses. The first trimester corresponded from 0 to 93 days ( $n=6$ UC; group1; Fig. 1a), the second trimester from 94 to 187 days of pregnancy ( $n=6 \mathrm{UC}$; group 2; Fig. $1 \mathrm{~b}$ ) and a further 6 umbilical cords were from the third trimester, with the 188-term of pregnancy corresponding to group 3 (Fig. 1c). UCs were collected according to the Animal Care Committee at the University of São Paulo State, Brazil and were conserved at room temperature in sterile phosphate-buffered saline (PBS) supplemented with a penicillin/streptomycin solution containing penicillin $100 \mu \mathrm{g} / \mathrm{ml}$, streptomycin
$10 \mu \mathrm{g} / \mathrm{ml}$ and amphotericin B $250 \mu \mathrm{g} / \mathrm{ml}$ (Sigma-Aldrich, St Louis, MO, USA) until use (within 3 h). Bovine umbilical segments were sectioned longitudinally to expose the $\mathrm{WJ}$ after $3 \mathrm{~h}$. Some incisions were made on the matrix and UC fragments were transferred to $25-\mathrm{cm}^{2}$ tissue culture flasks $\left(\right.$ TPP $^{\circledR}$, Zollstr, SW, Brazil). The initial culture and cell expansion were performed as described previously (Cardoso et al. 2012). Images were taken to observe cell morphology for each group at passage 6 (P6) (Fig. 1d-f), harvested and expanded until they reached subconfluence and then analyzed for their capacity for colony-forming, viability, T-cell proliferation, telomerase activity, phenotype and differentiation as well as for immunomodulatory transcripts.

\section{Cell viability, T-cell proliferation, telomerase activity and cell expansion}

Assays for cell viability, T-cell proliferation and telomerase activity were performed according to a previous study (Cardoso et al. 2012). Briefly, cell viability analysis was performed using the In Vitro Toxicology Assay ${ }^{\circledR}$ Kit, MTT-based assay (TOXI-1 Kit; Sigma-Aldrich) following the manufacturer's instructions. In order to evaluate T-cell proliferation, culture and stimulation were performed according to a previous study (Cardoso et al. 2012). Lymphoproliferation was evaluated as counts per minute by a Matrix 9600 beta counter (Packard Instrument, Meridien, CT, USA). The ConA was used at $5 \mu \mathrm{g} / \mathrm{ml}$ and PMA and ionomycin at concentrations of $50 \mathrm{ng} / \mathrm{ml}$ and $1 \mu \mathrm{g} / \mathrm{ml}$, respectively (Sigma-Aldrich). A TRAPeze ${ }^{\circledR}$ Telomerase Detection Kit (Millipore, CA, USA) was used to assess the telomerase activity in all groups (Cardoso et al. 2012). The samples were considered positive when the optical density (OD) was $\geq 0.2$ and negative when OD was $\leq 0.2$. All reported values are means of triplicate samples.

Doubling time for passages 1-10 was performed following the procedure described previously (Corradetti et al. 2013). Data representative of three independent experiments were recorded.

\section{In vitro multilineage differentiation assay}

The differentiation potential of bovine-derived WJMSC cells was examined using cells at passage number 6 (P6) in all cell groups according to a previous study (Cardoso et al. 2012; Silva et al. 2016). For all procedures $2 \times 10^{5}$ cells $/ \mathrm{ml}$ were submitted to osteogenic, chondrogenic, adipogenic and neurogenic differentiation according to the manufacturer's instructions (STEMPRO ${ }^{\circledR}$ differentiation medium; Invitrogen). The neurogenic differentiation was adapted from previous studies (Oda et al. 2013). For osteogenic/chondrogenic differentiation, $2 \mathrm{ml}$ of STEMPRO ${ }^{\circledR}$ osteogenic/chondrogenic 
Fig. 1 Bovine umbilical cords analyzed in this study. a 0-93 days corresponding to group 1 ; b 94 187 days corresponding to group 2; c 188 -term of pregnancy

corresponding to group 3 , bar $500 \mu \mathrm{m}$. d Ex vivo cultured cell obtained from Wharton's jelly zone corresponded to group 1, e group 2 and $\mathbf{f}$ group 3. After P6, spindleshaped fibroblast-like appearance can be observed under phase contrast microscopy. Bar $40 \mu \mathrm{m}$
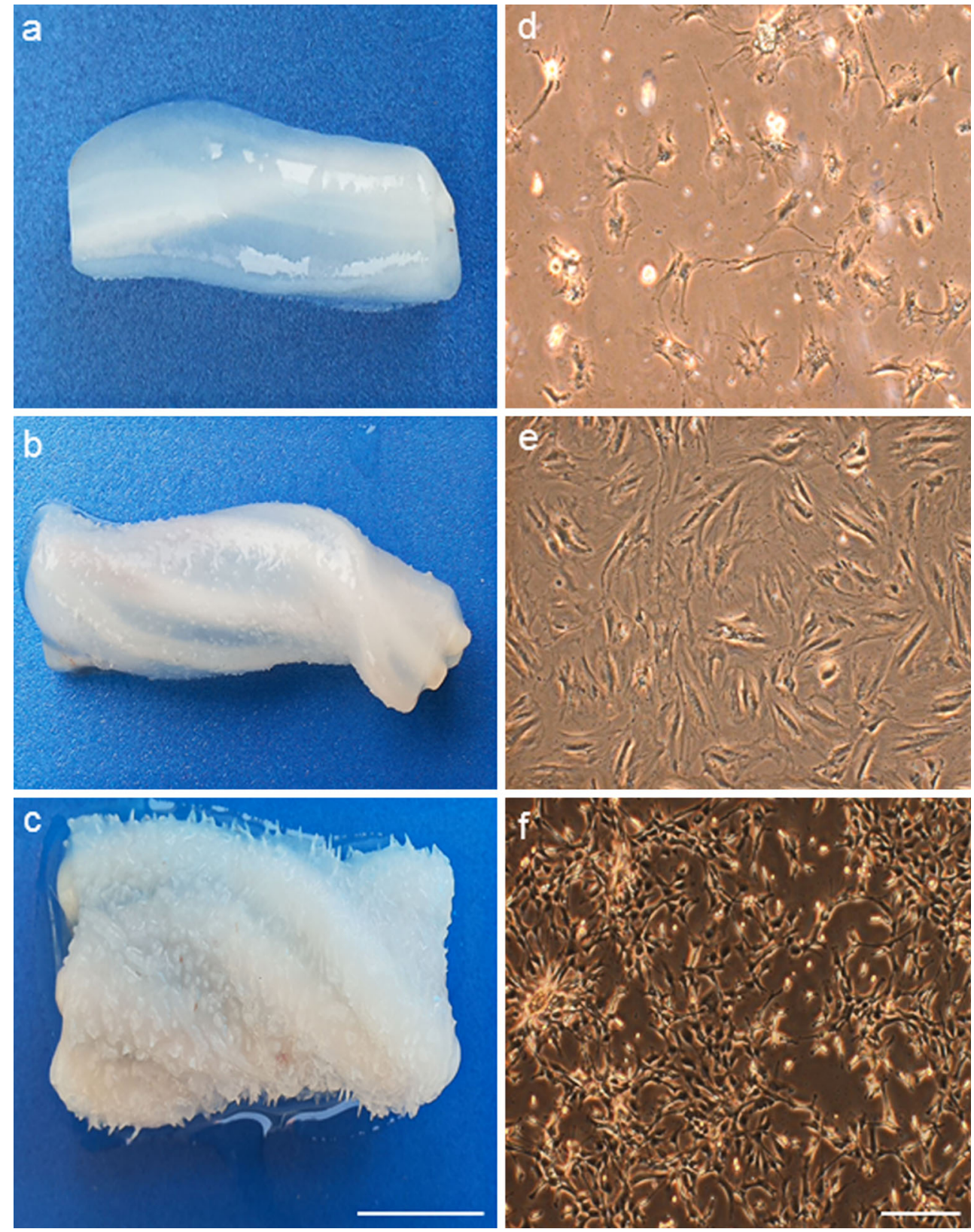

differentiation medium was added to undifferentiated cultures comprising osteogenic and chondrogenic commercial inducers $\left(\mathrm{STEMPRO}^{\circledR}\right)$. After 15 days of differentiation, cells were fixed with $4 \%$ paraformaldehyde (Sigma-Aldrich). For osteogenic differentiation, Alizarin Red staining (SigmaAldrich) was performed (Yang et al. 2015); and for chondrogenic differentiation $0.5 \%$ toluidine blue solution was added (Cardoso et al. 2012).

The adipogenic differentiation followed the described protocol (Cardoso et al. 2012; Silva et al. 2016). In order to verify adipocytes, Oil Red staining was performed (Cardoso et al. 2012). The differentiation of bovine-derived WJMSC cells into neural-like cells followed the procedure described previously, with some modifications (Cardoso et al. 2012; Oda et al. 2013; Silva et al. 2016). The neuronal differentiation was confirmed by immunofluorescence for GFAP and nestin cell markers, as described previously (Cardoso et al. 2012). From each experiment, samples from cell differentiation and undifferentiated cells were harvested for multilineage gene transcription among the three studied groups as described below.

\section{Flow cytometry}

Briefly, $2 \times 10^{5}$ cells at P6 were harvested, washed in PBS and incubated for $18 \mathrm{~h}$ at $4{ }^{\circ} \mathrm{C}$ with monoclonal antibodies: CD34 (hematopoietic precursor cells and MSCs); CD45 (anti-bone marrow lymphoid cells); CD90 (anti-THy1 antigen); CD105 
Table 1 Specifications of (Bos taurus) cattle gene name, description and location searched by microarray

\begin{tabular}{|c|c|c|c|}
\hline Gene symbol/ID & & Description & Location \\
\hline \multicolumn{4}{|c|}{ Positive markers of MSCs } \\
\hline$E N G$ & 615.844 & Endoglin (CD105) & Chromosome 11, AC_000.168.1 \\
\hline ITGBI & 281.876 & Integrin, beta 1 (CD29) & Chromosome 13 AC_000.170.1 \\
\hline NT5E & 281.363 & 5'nucleosidase ecto (CD73) & Chromosome 9, AC_000.166.1 \\
\hline THY1 & 614.712 & Thy- 1 cells surface antigen (CD90) & Chromosome 15, AC_000.171.1 \\
\hline$C D 34$ & 281.051 & Hematopoietic progenitor cell antigen (CD34) & Chromosome 16, AC_000.954.1 \\
\hline PTPRC & 407.152 & Protein tyrosine phosphatase, receptor type C (CD45) & Chromosome 16, AC_000.173.1 \\
\hline JSP.1 & 407.173 & Major histocompatibility complex class I (MHCI) & Chromosome 23, AC_000.180.1 \\
\hline$D S B$ & 618.722 & $\begin{array}{l}\text { Major histocompatibility complex class II, antigen DS } \\
\text { beta (MHC II) }\end{array}$ & Chromosome 23, AC_000.180.1 \\
\hline \multicolumn{4}{|c|}{ Immune-related genes } \\
\hline IFNAC & 281.236 & Interferon alpha $\mathrm{C}$ (INF-alpha $\mathrm{C}$ ) & Chromosome 8, AC_000.165.1 \\
\hline INFBI & 281.845 & Interferon, beta 1 , fibroblast & Chromosome 8, AC_000.165.1 \\
\hline$I F N G$ & 281.237 & Interferon, gamma & Chromosome 5, AC_000.162.1 \\
\hline IL2 & 280.822 & Interleukin 2 & Chromosome 17, AC_000.174.1 \\
\hline$I L 6 R$ & 507.359 & Interleukin 6 receptor & Chromosome 5, AC_000.162.1 \\
\hline IL1F10 & 615.702 & Interleukin 1 , family member 10 & Chromosome 11, AC_000.168.1 \\
\hline$T N F$ & 280.943 & Tumor necrosis factor (TNF alpha) & Chromosome 23, AC_000.180.1 \\
\hline$L T B R$ & 280.845 & Lymphotoxin beta receptor (TNF superfamily member 3) & Chromosome 5, AC_000.162.1 \\
\hline \multicolumn{4}{|c|}{ Positive markers of MSCs multipotency } \\
\hline$L E P$ & 280.836 & Leptin & Chromosome 4, AC_000.161.1 \\
\hline$F A B P 4$ & 281.759 & Fatty acid binding protein 4 , adipocyte & Chromosome 14, AC_000.171.1 \\
\hline PPARD & 353.106 & Perixome proliferator-activated receptor delta & Chromosme 23, AC_000.180.1 \\
\hline COL1A1 & 282.187 & Collagen type 1 , alpha 1 & Chromosome 19, AC_000.176.1 \\
\hline SOX9 & 353.115 & SRY (sex determining region Y)-box 10 & Chromosome 5, AC_000.162.1 \\
\hline GFAP & 281.189 & Glial fibrillary acidic protein & Chromosome 19,AC_000.176.1 \\
\hline$N E S$ & 522.383 & Nestin & Chromosome 3, AC_000.160.1 \\
\hline$O M D$ & 280.885 & Osteomodulin & Chromosome 8, AC_000.0149.1 \\
\hline POST & 281.960 & Osteoblast specific factor & Chromosome 12, AC_000.034.1 \\
\hline OSTF1 & 281.961 & Osteoclast stimulating factor 1 & Chromosome 8, AC_000.0610.1 \\
\hline
\end{tabular}

(anti-endoglin); CD29 (anti-integrin $\beta 1$ ) all diluted at 1:50; CD73 (anti-nucleotidase) diluted at 1:25 (Sigma-Aldrich). Next, cells were washed three times with PBS plus $0.1 \%$ Triton X-100 and 1:50 dilution of the secondary antibody, represented by goat anti-mouse labeled to FITC (SigmaAldrich), was added to $100 \mu \mathrm{l}$ of cell suspension and incubated at $37{ }^{\circ} \mathrm{C}$ for $30 \mathrm{~min}$. The cell suspension was washed as previously described and after the final wash, cells were fixed with $4 \%$ paraformaldehyde. Data were captured with the Attune $^{\text {TM }}$ acoustic focusing cytometer system (Applied Biosystems, Foster City, CA, USA). The equipmental settings were defined as an initial threshold: 2.500 events/s, BL1A filter (488 nm emission) 300 voltage, SSC (scatter complexity) $250 \mathrm{~V}$ and FSC (forward scatter) $220 \mathrm{~V}$. After the first acquisition, a dot plot graph was obtained and a global compensation was performed to exclude unspecific signals and cell debris ( $>10^{3}$ cells were excluded). Only one fluorophore was used in this analysis, so these parameters could be applied in all analyses. The data were expressed in histograms.

\section{Microarray analysis}

Total RNA was isolated from all groups, corresponding to WJMSCs $\left(5 \times 10^{5}\right.$ cells $)$ in triplicate after trypsinization, according to the Qiagen RNeasy System ${ }^{\mathrm{TM}}$ (Qiagen, Hilden, Germany) manufacturer's guide. The total RNA was treated

Fig. 2 Cell viability, inhibition of T-cell proliferation and telomerase activity. a Viability of WJMSC cells measured by MTT based assay at 2, 6 and 10P. Data are expressed as mean \pm standard deviation (SD) of values obtained from four different experiments. b Ability of bovine WJMSCs cells to inhibit T-cell proliferation in response to mitogens at $6 \mathrm{P}, P<0.005$ obtained from four different experiments. c Telomerase repeat amplification results obtained from four different experiments. Bars represent all groups at $2 \mathrm{P}, 6 \mathrm{P}$ and $10 \mathrm{P}$ 

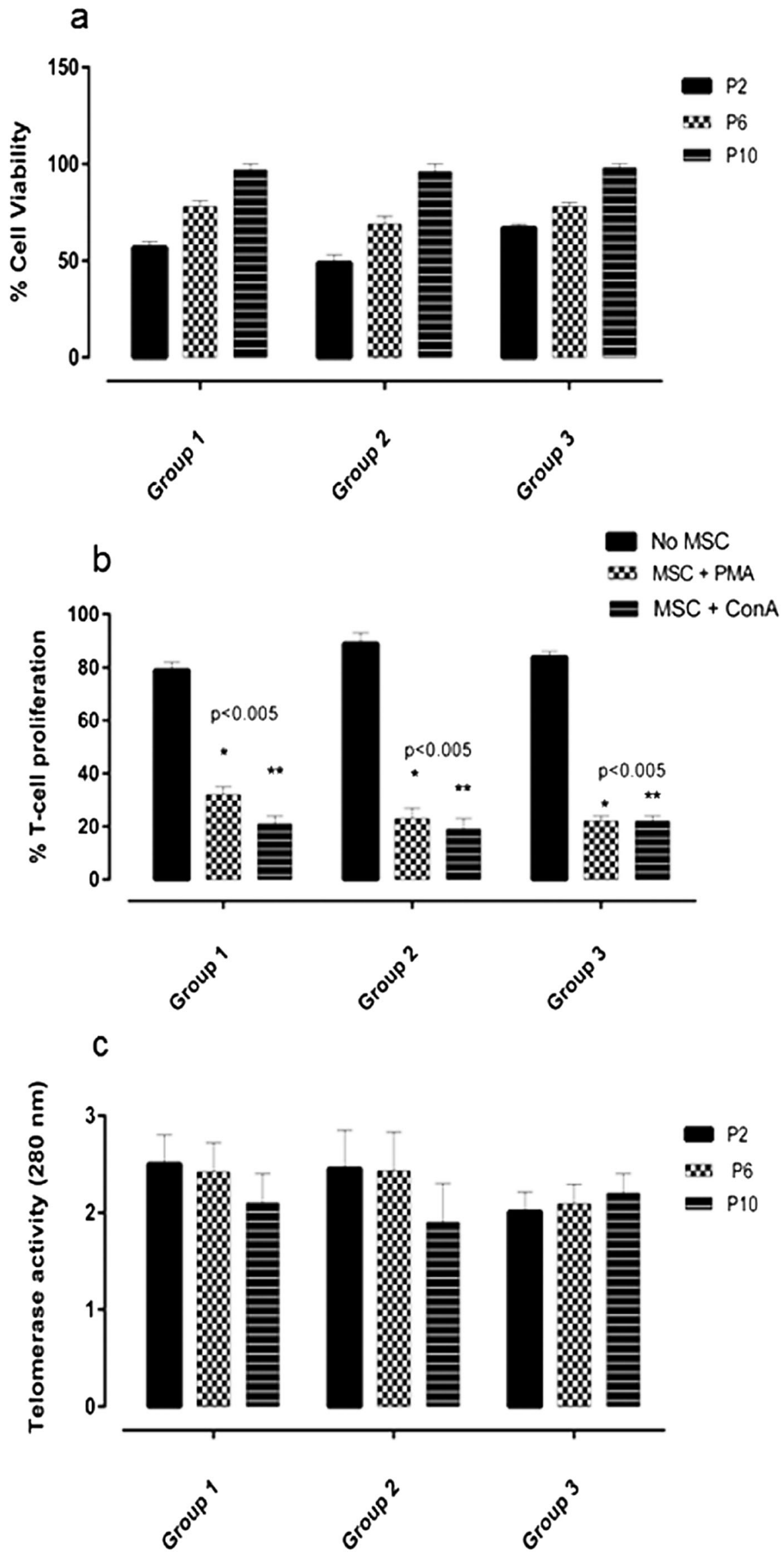
with DNAse and reverse transcribed into cDNA using a reverse transcriptase (Superscript III; Life Technologies, Carlsbad, CA, USA). The Axiom ${ }^{\circledR}$ Genome-Wide BOS 1 Array was used for transcriptome analysis (Affymetrix, Santa Clara, CA, USA). This commercial array was designed to maximize genetic coverage of commercially important cattle breeds, including Bos taurus, Bos indicus and dairy and beef cattle breeds. The array covers more than 640,000 validated transcript markers representing the genetic diversity of approximately 3 million from the Affymetrix Bovine Genomic Database. After hybridization, the gene chips were washed and stained with SA-PE and read using an Affymetrix Gene Chip fluidic station and scanner. Analyzed genes, corresponding to positive markers of MSCs, immune-related genes and MSCs multipotency, are detailed in Table 1. The average expression was calculated and $\log _{2}$-transformed for each gene by Affymetrix Microarray Suite 5.0.

\section{Statistical analysis}

All statistical analyses were performed using the SAS 9.1.2 software package (SAS Institute). Data are presented as mean \pm SD. Three replicates for each experiment were performed and the results represent these replicates. We executed oneway analysis of variance (ANOVA) for multiple comparisons or two-tailed Student's $t$ test, whenever applicable by GraphPad Prism 6.05. A level of $P<0.005$ was accepted as significant.

\section{Results}

\section{Isolation and characterization of WJMSCs}

WJMSCs were cultured individually only during the first passage. After P1, all WJMSCs from each group were transferred to a unique culture flask and proceeded as lineages. The formation of fibroblast-like cells was observed around the second day and in vitro cell expansion was performed until 10 consecutive passages for all groups (Fig. 1d-f).

The culture conditions were able to promote good cell viability, $>80 \%$ after $10 \mathrm{P}$ for all groups; induced inhibition of T-cell proliferation; telomerase activity at satisfactory levels (Fig. 2a-c, respectively). The percentage of living cells was maintained approximately constant when the passage number remained at a constant level of 10 (Fig. 2a). The addition of WJMSC cells to blood monocytes stimulated with ConA or PMA/ionomycin inhibited their proliferation less than $20 \%$ in comparison to no addition of WJMSC cells, whereas $80 \%$ of proliferation for all groups was observed $(P<0.005)$. In addition, the activity of telomerase was verified and in all groups after 6P the same activity could be observed (Fig. 2c). The doubling time was measured, calculated and drawn as a graph, where a consistent increasing rate of growth at P6 was observed for each group, respectively (Figs. $3 a-c$ and 4).

\section{Multilineage differentiation and phenotypic characterization}

Pluripotency was confirmed by the ability of WJMSCs cells to differentiate into osteocytes, adipocytes, chondrocytes and neuron-like cells. Undifferentiated cells were included in all analyses (Fig. 3a, e, i, corresponding to groups 1, 2 and 3, respectively). Osteogenic differentiation was detected by the matrix calcification shown by Alizarin Red staining (Fig. 3b, $\mathrm{f}, \mathrm{j}$, corresponding to groups 1,2 and 3 , respectively). After induction, adipogenic differentiation with a high number of very small lipid vacuoles that stained positively using Oil Red solution was visualized in groups 1, 2 and 3 (Fig. 3c, g, 1, respectively). Chondrogenic differentiation was confirmed by blue deposits representing glycosaminoglycans (Fig. 3d, $\mathrm{h}, \mathrm{m}$, corresponding to groups 1,2 and 3 , respectively). The neurogenic induction was confirmed by positive staining for GFAP and nestin neuro markers in group 1 (Fig. 5b, c), group 2 (Fig. 5e, f) and group 3 (Fig. 5h, i). Undifferentiated cells were also included in groups 1, 2 and 3 as control (Fig. 5a, d, g, respectively).

The phenotype of WJMSCs obtained from three groups was characterized using flow cytometry (FC) analysis (Figs. 6, 7 and 8 corresponding to groups 1,2 and 3 , respectively). All WJMSCs revealed negative results for CD45 and CD34 surface markers at FC analysis in groups 1, 2 and 3 (Figs. 6a, b, $7 \mathrm{a}, \mathrm{b}$ and $8 \mathrm{a}, \mathrm{b}$, respectively). However, positive results for CD105, CD29, CD73 and CD90 surface markers were recorded at the same rate of $10^{4}$ cells for all groups (Figs. 6, 7, 8). In group 1 (Fig. 6c), CD105-positive cells were considered at a lower rate $(45 \%)$ when compared to group 2 (81\%; Fig. 7c). However, in groups 2 and 3 (Figs. 7e, f, and 8e, f, respectively), CD73 (92\% and $78 \% ; P<0.005)$ and CD90 (96\% and $79 \%)$ were more highly expressed, respectively $(P<0.005)$. In comparison, group 2 revealed superior expression of positive markers of MSCs in this study (Fig. 7a-f).

\section{Gene expression profile}

Genes described as being involved in MSCs characterization revealed consistent results with flow cytometric analysis. High transcription levels for MSCs markers THY1 (CD90), NT5E (CD73), ITGB1 (CD29), ENG (CD105) and low levels for CD34 and PTPRC (CD45) were found among WJMSCs

Fig. 3 Doubling time over 10 passages during cell culture from group 1 (a), 2 (b) and 3 (c). $X$-axis is represented by number of cell passage and $Y$ axis by days of culture. Data are expressed as mean \pm standard deviation (SD of values obtained from four different experiments). $* P<0.05$ 

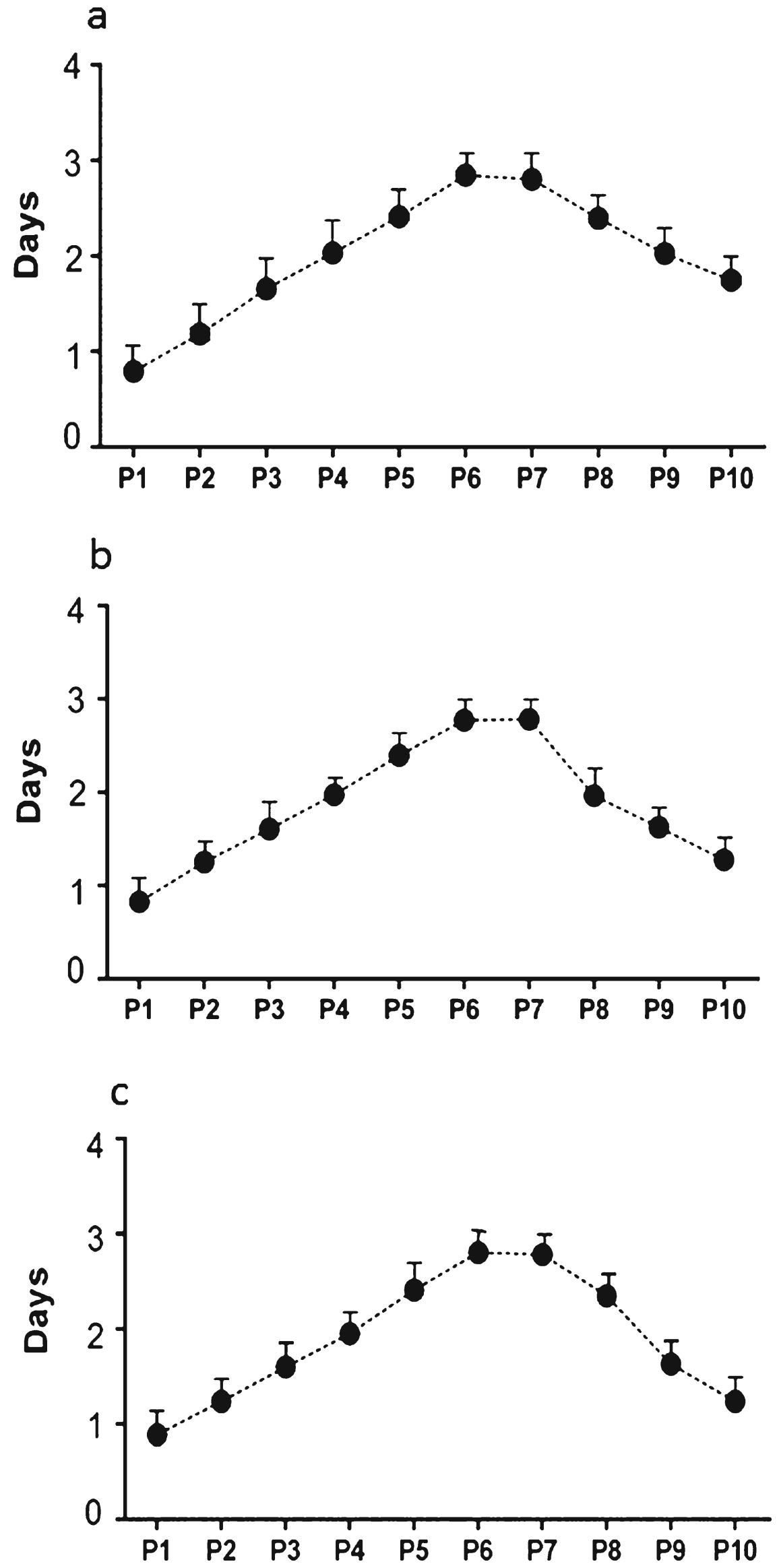


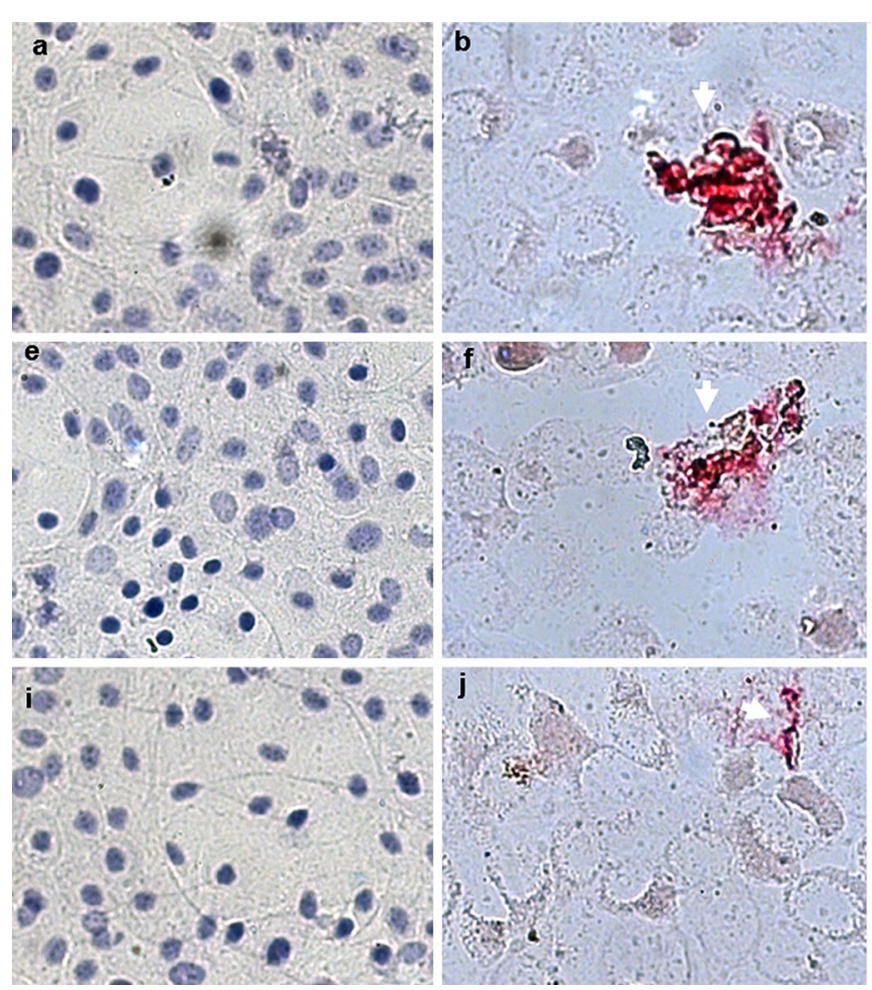

Fig. 4 Photomicrographs representative of the morphological appearance. For each differentiation protocol, undifferentiated cells were kept as controls for group 1 (a), 2 (e) and 3 (i). Osteogenic differentiation was confirmed after Alizarin Red staining (group $4 \mathbf{b}$, group $4 \mathbf{f}$ and group $4 \mathbf{j}$; arrows), adipogenic differentiation after Oil
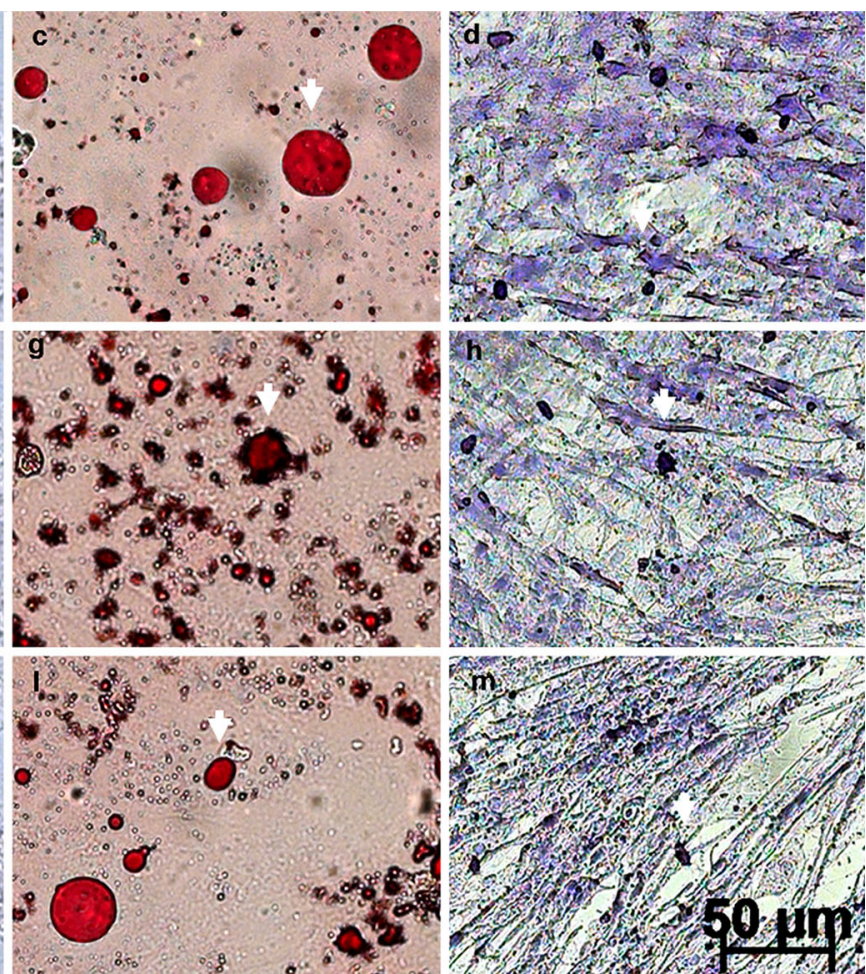

Red staining (group $4 \mathbf{c}$, group $4 \mathbf{g}$ and group $4 \mathbf{l}$; arrows) and chondrogenic differentiation after Toluidine blue staining (group $4 \mathbf{d}$, group $4 \mathbf{h}$ and group $4 \mathbf{m}$; arrows) and differentiation of bovine-derived WJMSCs cells at P6
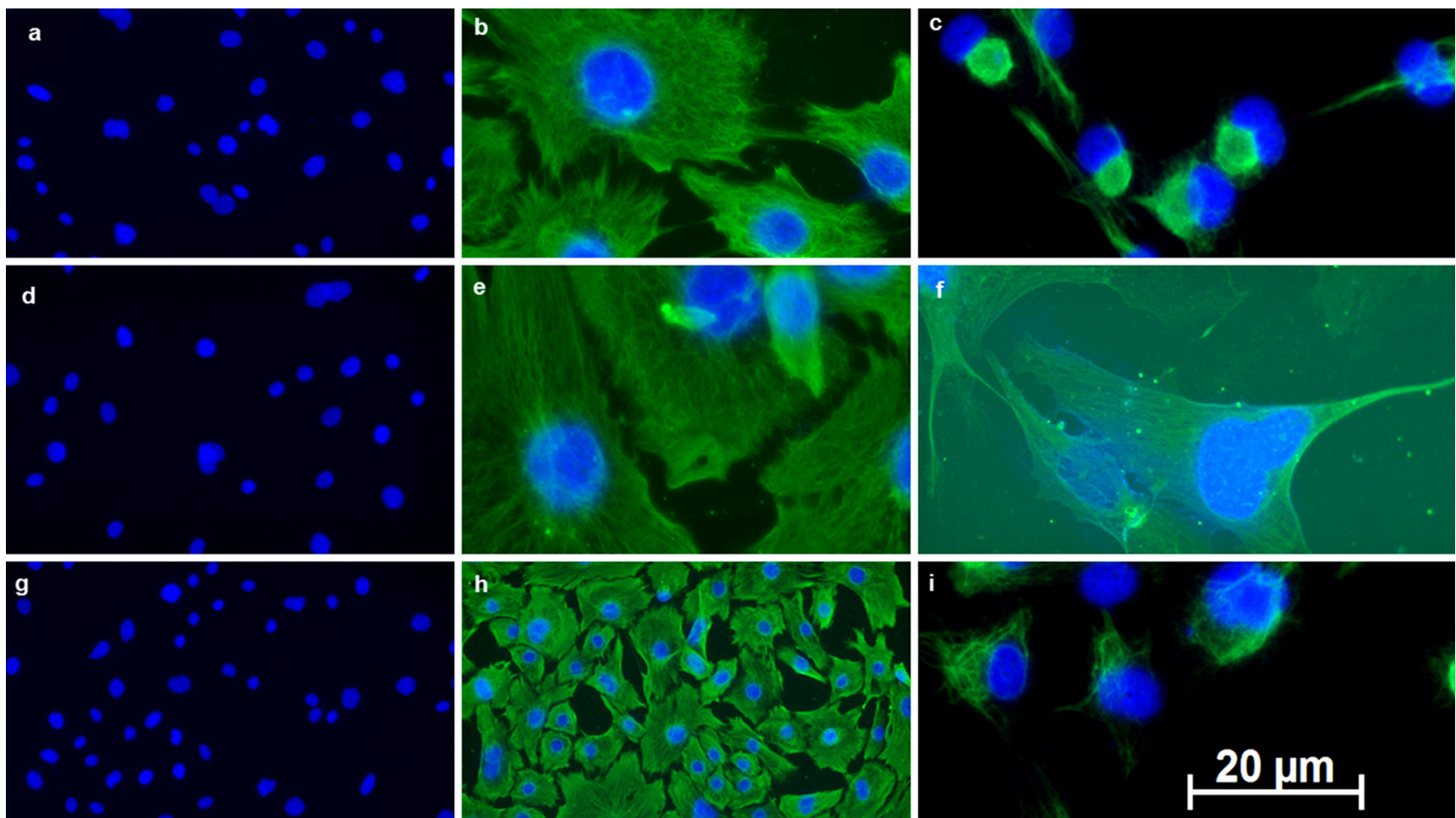

Fig. 5 Photomicrographs representative of the morphological appearance of neuro-like cells after neurogenic induction visible under immunofluorescence microscopy positive GFAP (group $1 \mathbf{b}$; group $2 \mathbf{e}$; group $3 \mathbf{h}$ ) and Nestin (group $1 \mathbf{c}$; group $2 \mathbf{f}$ and group $3 \mathbf{i}$ ) cell markers (scale bar $20 \mu \mathrm{m}$ ). Undifferentiated cells were kept as controls for groups 1 (a), 2 (d) and 3 (g) 
Fig. 6 Flow cytometry analysis of WJMSCs surface markers corresponded to group 1. X-axis corresponds to the number of positive labeled cells detected by the BL1A filter (488 nm). Y-axis is cell count (log scale). The data obtained from four different experiments were processed using an Attune ${ }^{\mathrm{TM}}$ acoustic focusing cytometer. For CD45 and CD34, data are illustrated in $(\mathbf{a}, \mathbf{b})$ (group 1). For CD105, CD29, CD73 and CD90 the results are illustrated in (c-f)
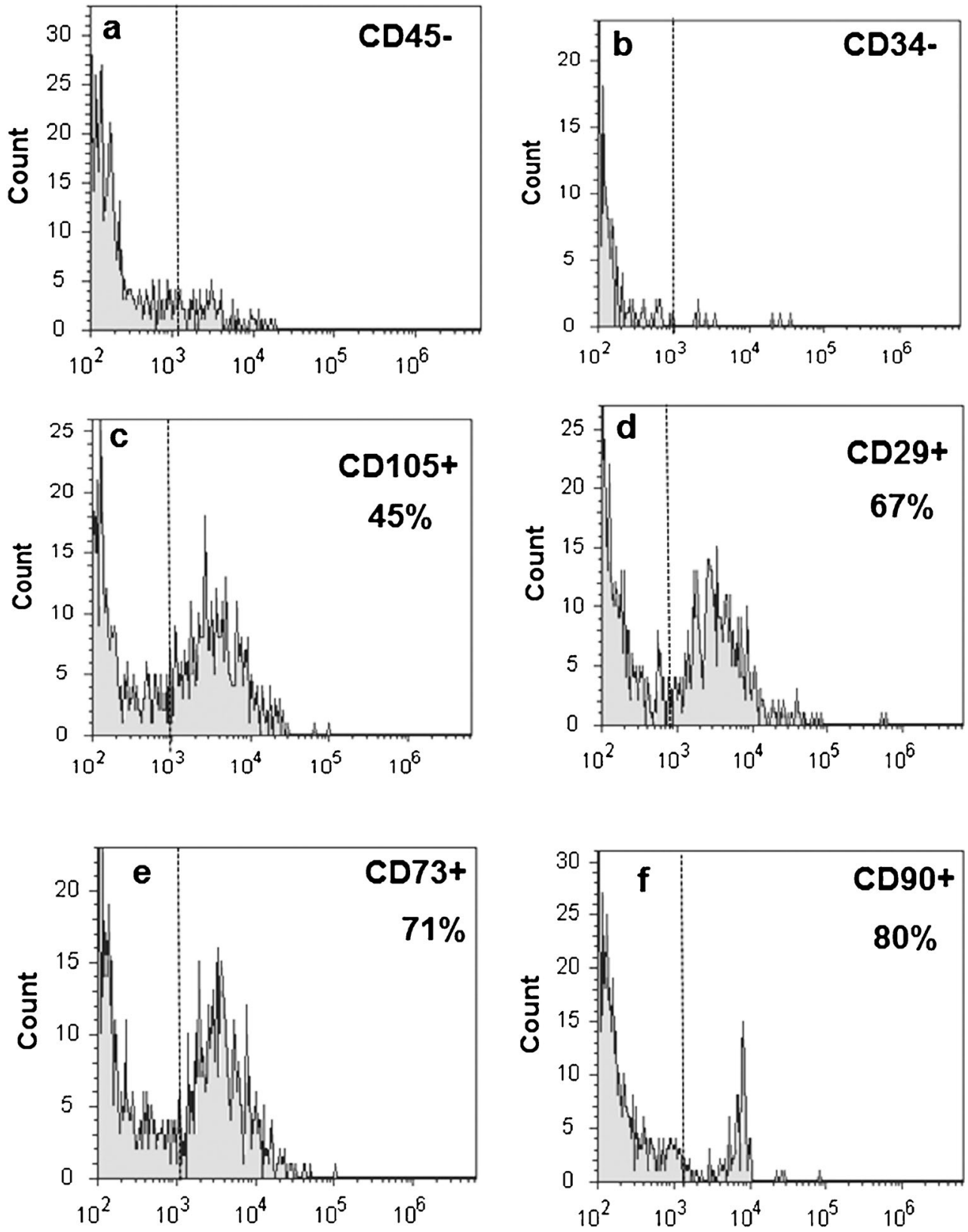

(Fig. 9a-c). When stimulated to differentiate towards adipogenic, chondrogenic and neurogenic lineages, WJMSCs showed substantial transcriptional expression of LEP, FABP4, PPARD, COL1A1, SOX9, GFAP and NES for all WJMSCs (Fig. 9a-c). The WJMSCs potential to undergo chondrogenesis showed a higher pattern of COL1A1 gene expression at group 2 in comparison to groups 1 and 3 (Fig. 9b). From the factors measured in this study, IL2, IL6R, INFAC, INFB1, $I N F G, T N F$ and $L T B$, considered pro-inflammatory cytokines, were genetically downregulated in all WJMSCs tested (Fig. 9ac; $P<0.005$ ). However, IL1F10 was noticeably upregulated, in microarray analysis (Fig. 9a). The lack of JSP.1 and $D S B$ (MHCI and II) expression could be observed in this study amongst WJMSCs from all groups (Fig. 9a-c).

\section{Discussion}

Extra gestational tissues have been widely suggested as ideal sources of mesenchymal cells due to their noninvasive harvest and most of the time being discarded biological material (Troyer and Weiss 2008; Iacono and Merlo 2015). Currently, limited reports are available regarding the isolation and characterization of Wharton's jelly-derived MSCs in farm animal species (Carlin et al. 2006; Corradetti et al. 2008; Cardoso et al. 2012; Singh et al. 2013). WJMSCs demonstrated, at all gestational periods, satisfactory telomerase activity, viability and MSCs surface markers according to previous studies (Cardoso et al. 2012). In spite of the fact that non- 
Fig. 7 Flow cytometry analysis of WJMSCs surface markers corresponded to group 2. X-axis corresponds to the number of positive labeled cells detected by the BL1A filter (488 nm). Y-axis is cell count (log scale). The data obtained from four different experiments were processed using an Attune ${ }^{\mathrm{TM}}$ acoustic focusing cytometer. For CD45 and CD34, data are illustrated in $(\mathbf{a}, \mathbf{b})$ (group 2). For CD105, CD29, CD73 and CD90, the results are illustrated in (c-f)
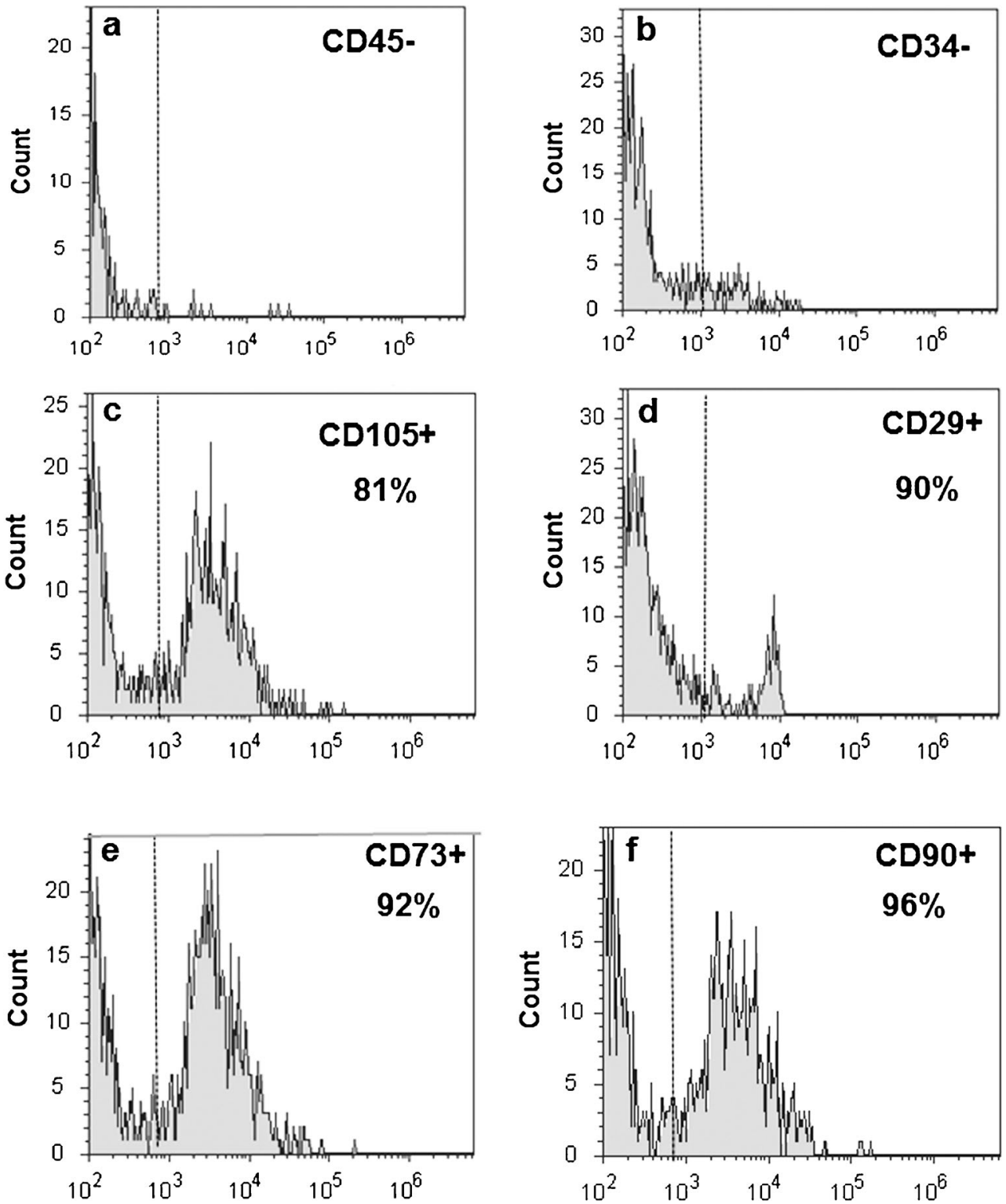

bovine monoclonal antibodies were used here, several reports have described cross-reaction between animals and human MSCs epitopes (Godoy et al. 2014). Moreover, THY1 (CD90), NT5E (CD73), ITGB1 (CD29) and $E N G$ (CD105) transcripts were confirmed by flow cytometric analysis, confirming the stem cell potential of WJMSCs in this study.

Studies on the isolation and characterization of MSCs from fetal adnexa in humans are advancing rapidly (Troyer and Weiss 2008; Weiss et al. 2008; Corrao et al. 2013; Gottipamula et al. 2013). Some authors have reported that MSCs isolated from human umbilical cord matrix, precisely from Wharton's jelly, could be used for therapy of some diseases such as amyotrophic lateral sclerosis and Parkinson's disease, even in cancer treatment (Troyer and
Weiss 2008; Corrao et al. 2013). However, studies in animal models are still in their infancy. MSCs have been isolated from umbilical cord matrix of cattle, pigs, goats, horses and dogs (Uranio et al. 2011; Cremonesi et al. 2008; Cardoso et al. 2012). The bovine model could have a critical role in studying fetal adnexa MSC sources, mainly through the similarity to human gestational time. Our study aimed specifically to isolate, expand in vitro, and characterize WJMSCs harvested at different gestational stages. Previous studies have reported the isolation of WJMSCs from bovine umbilical cord at birth, successfully growing them in culture without fetal calf serum showing pluripotency capacity (Cardoso et al. 2012; Silva et al. 2016). Moreover, a recent study demonstrated that bovine MSCs isolated from amniotic fluid and adipose tissue could be an alternative for nuclear 
Fig. 8 Flow cytometry analysis of WJMSCs surface markers corresponded to group 3. X-axis corresponds to the number of positive labeled cells detected by the BL1A filter (488 nm). Y-axis is cell count (log scale). The data obtained from four different experiments were processed using an Attune ${ }^{\mathrm{TM}}$ acoustic focusing cytometer. For CD45 and CD34, data are illustrated in $(\mathbf{a}, \mathbf{b})$ (group 3). For CD105, CD29, CD73 and $\mathrm{CD} 90$, the results are illustrated in (c-f)
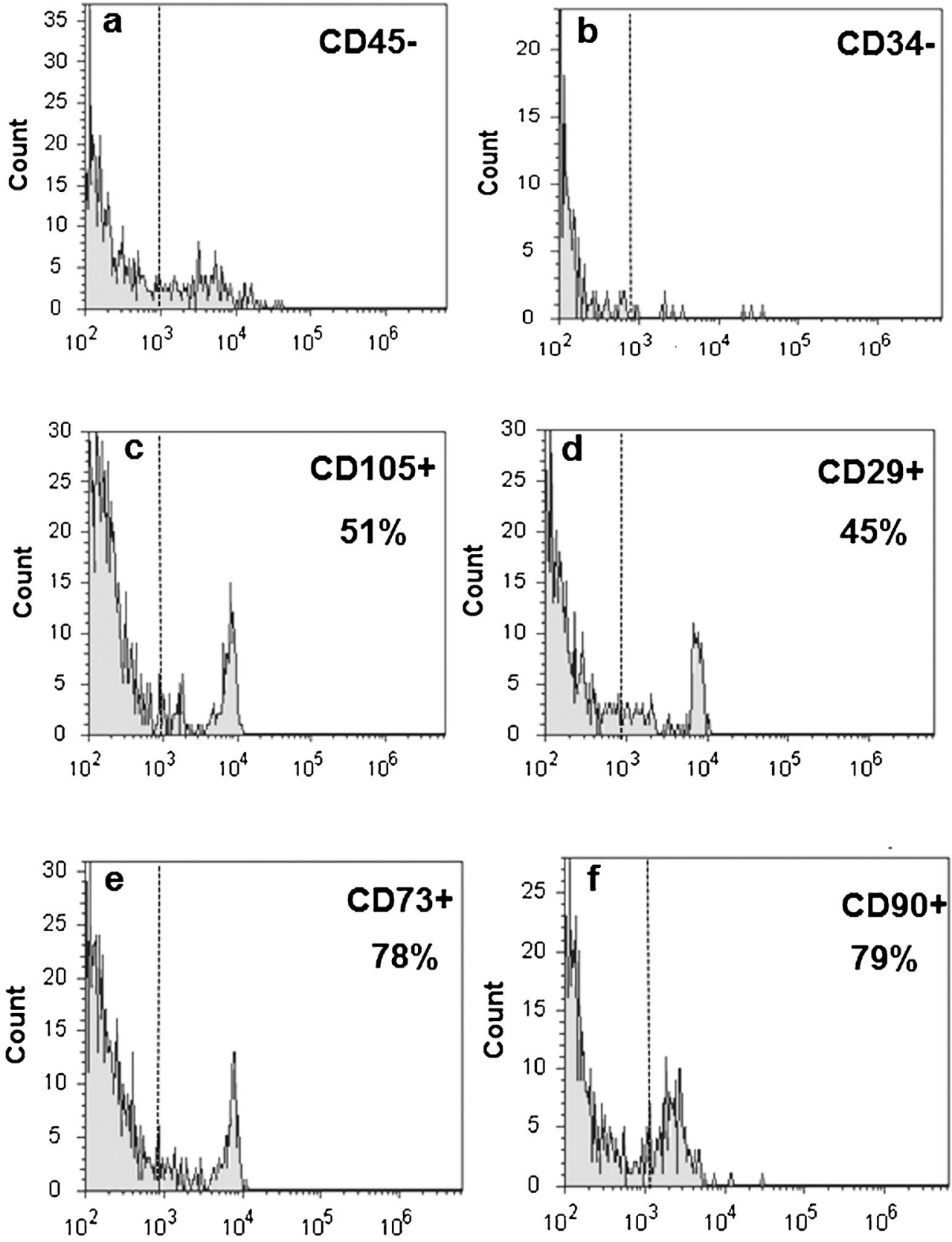

transfer (Silva et al. 2016). In both studies, the size of bovine MSC-derived WJ cells was found to be smaller when compared to human studies (Taghizadeh et al. 2011; Gottipamula et al. 2013; Pham et al. 2016) and ruminant MSCs were derived from different fetal adnexa sources (Cardoso et al. 2012; Corradetti et al. 2013; Cortes et al. 2013; Raoufi et al. 2011; Somal et al. 2016). This finding must be investigated in future studies.

The in vitro differentiation results support the findings already reported for bovine MSC ( $\mathrm{Lu}$ et al. 2011; Raoufi et al. 2011; Corradetti et al. 2013; Cortes et al. 2013). All WJMSCs show high plasticity, being able to differentiate into multiple germ layers, mesoderm and ectoderm. This is in agreement with all studies regarding bovine MSC and other species (Cremonesi et al. 2008; Uranio et al. 2011; Oda et al. 2013). WJMSCs, when stimulated to differentiate toward adipogenic lineage, expressed high levels of the $L E P$ gene that is regarded as an intermediate and late marker of adipocyte differentiation, which may lead to a distinct differentiation characteristic of stem cells in all gestational periods. The WJMSCs potential to undergo osteogenesis/chondrogenesis showed a higher pattern of expression of OMD, POST, OSTF1 and COL1A1 in all groups. As demonstrated previously, WJMSCs have a proven ability to undergo astrocyte differentiation, confirmed by GFAP expression already demonstrated for other species (Oda et al. 2013). Taking these results together, it seems that 
Fig. 9 Transcriptome analysis of WJMSCs surface markers, multipotency differentiation and immune related genes from groups 1, 2 and 3. Relative gene expression are represented as mean + SD obtained from four different experiments. Unbroken line is positioned on the average negative known markers of MSCs. Genes with relative expression values above this line were considered upregulated and were analyzed in comparison to control comprising the bovine Tlymphocyte population. a Group $1, \mathbf{b}$ group 2 and $\mathbf{c}$ group 3

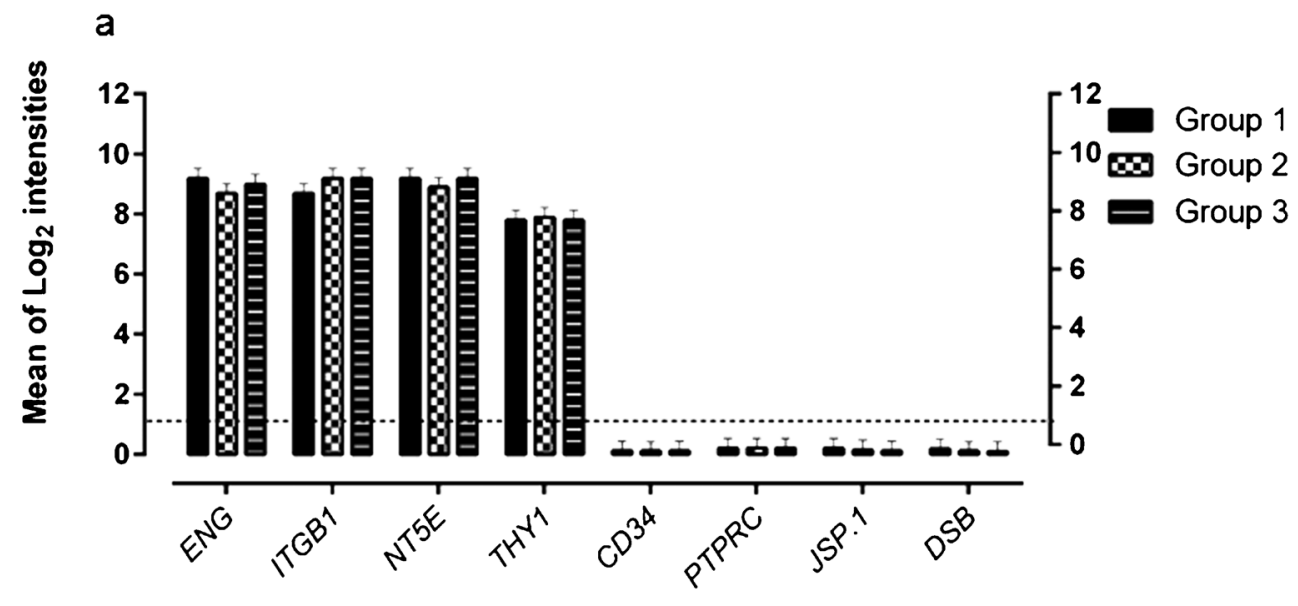

b Positive markers of MSCs

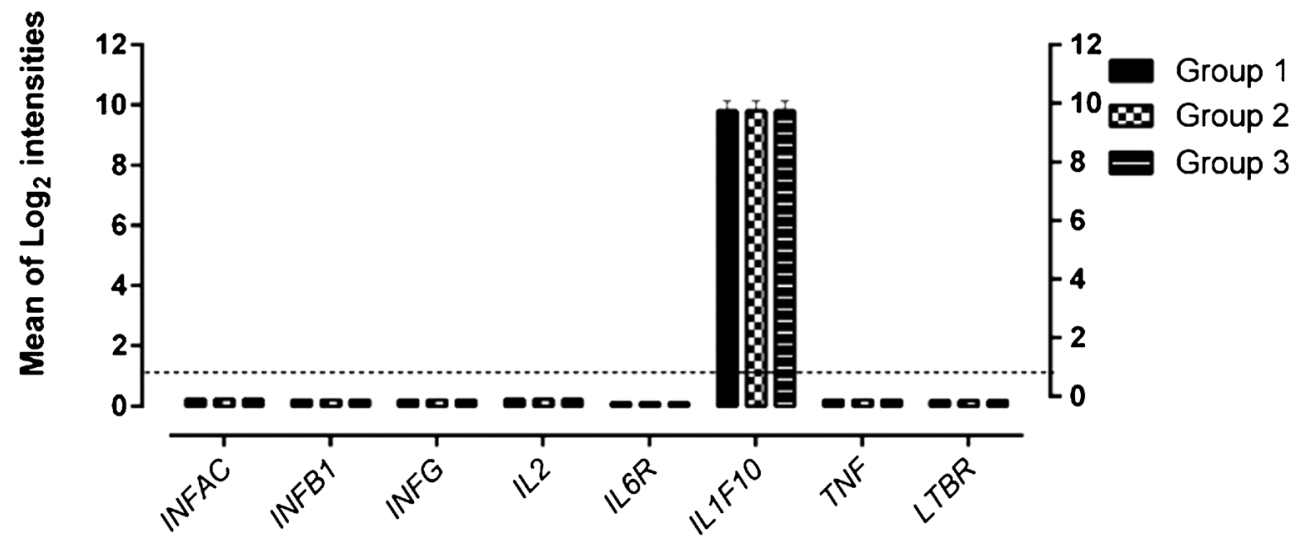

C

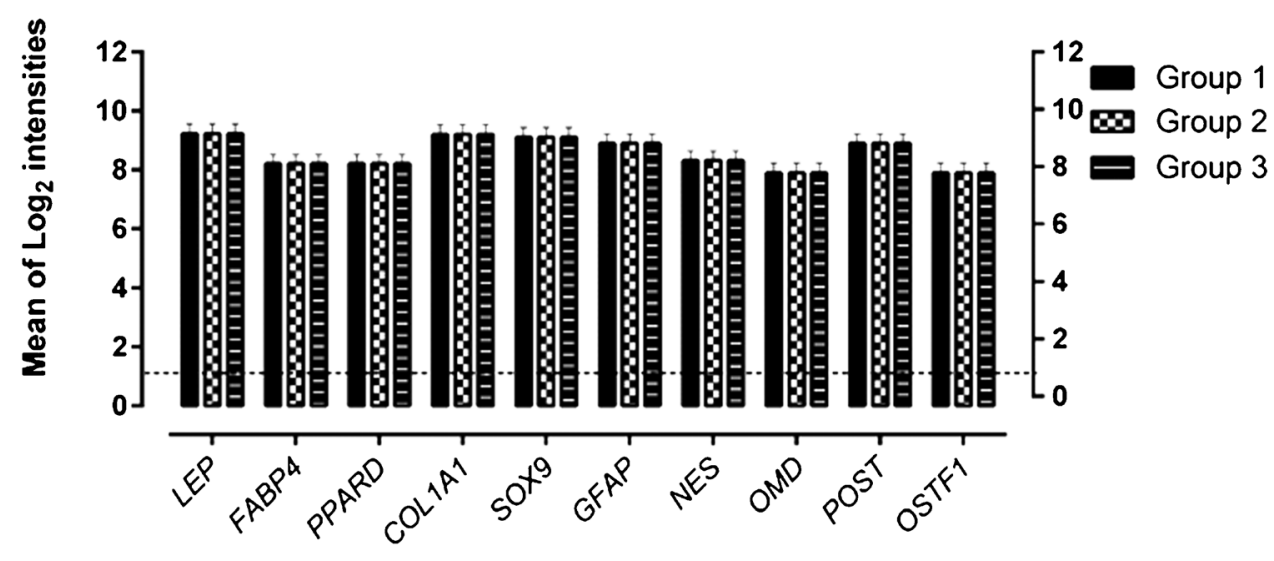

Positive markers of MSCs multipotency all gestational periods have provided WJMSCs with stemness attributed to MSCs according to the International Society for Cellular Therapy (Dominici et al. 2008).

Since MSCs are trapped within the Wharton's jelly between days 4 and 12 of embryonic development and reside there for the whole gestation, they can be harvested after the birth of the newborn and during pregnancy
(Taghizadeh et al. 2011). Therefore, WJMSCs that formed during the earliest ontogenic period result in a significant expansion potential compared to bone marrow mesenchymal cells (Troyer and Weiss 2008).

There is considerable controversy in the literature regarding the immunogenicity of human MSCs (Weiss et al. 2008; De Miguel et al. 2012; Mukonoweshuro 
et al. 2014) and a lack of information about bovine MSCs. However, porcine umbilical cord-derived stem cells did not induce a considerable immune response in vivo but stimulation with interferon gamma or injection in an inflamed region resulted in immunogenicity (Poncelet et al. 2007). Inflammatory situations prevail during any injury and MSCs could be exposed to such stimuli in many clinical conditions. Not only neighboring cells but also environmental factors like systemic or local inflammation can influence the immune behavior of MSCs (Poncelet et al. 2007). In fact, recent reports indicate the role of inflammatory cytokines in affecting functions of mouse MSCs (Mukonoweshuro et al. 2014).

From the factors measured in this study, IL2, IL6R, INFAC, INFB1, INFG, TNF and LTBR, considered proinflammatory cytokines, were genetically downregulated in all the bMSCs tested. IL10 cytokyne is produced by both myeloid and lymphoid cells. However, it is a good immune suppressor, although some stimulatory effects have been described. Therefore, IL10 cytokine is recognized by its effect on T-cells, macrophages and monocytes in suppressing inflammation processes (Prasanna et al. 2010; Mukonoweshuro et al. 2014). However, when ILIF10 is expressed it will downregulate JSP.1 (MHC I) as revealed in WJMSCs cultures. These findings are in accordance with what has been described in human MSCs (Weiss et al. 2008). The results described previously revealed that MSC possess immunosuppressive properties; however, they might not be immunoprivileged (De Miguel et al. 2012). The lack of DSB and low JSP.1 expression observed in this study is thought to be, in part, responsible for their WJMSC immunoprivileged status, which would mean allogeneic bovine MSC could be used without the risk of immune rejection, a scenario that is attractive for tissue comparative studies.

These findings demonstrated the complexity of studying the immunological properties of WJMSCs in vitro, as well as the difficulty of distinguishing between optimal gestational stages in order to collect Wharton's jelly cells with optimal stemness properties. Finally, WJMSCs collected from bovine umbilical cord at all gestational periods showed similar stemness properties.

\footnotetext{
Acknowledgments The authors thank the cattle owners for their cooperation in the specimen collection at slaughterhouses. This work was supported by Fundação de Amparo à Pesquisa do Estado de São Paulo (Grants 2012/16715-4). T.C. Cardoso and E.F. Flores are recipients of $\mathrm{CNPq}$ (Brazilian Council for Research) funding.

Author's contributions TCC participated in the design of the study, performed the cell culture in all steps and flow cytometric analysis. LHO and JCB participated in the preparation of respective umbilical cords. RG and HLF participated also in the design of the study, performed the statistical analysis and drafted the manuscript. MM and EFF drafted the final version of the manuscript.
}

Compliance with ethical standards

Conflict of interest The authors indicate no conflicts of interest.

\section{References}

Calloni R, Viegas GS, Turck P, Bonatto D, Henriques JAP (2014) Mesenchymal stromal cells from unconventional model organisms. Cytotherapy 16:3-16

Cardoso TC, Ferrari HF, Garcia AF, Novais JB, Silva-Frade C, Ferrarezi MC, Andrade AL, Gameiro R (2012) Isolation and characterization of Wharton's jelly derived multipotent mesenchymal stromal cells obtained from bovine umbilical cord and maintained in a define serum-free three dimensional system. BMC Biotechnol 12:18

Carlin R, Davis D, Weiss M, Schuktz B, Troyer D (2006) Expression of early transcription factor Oct-4, Sox-2 and Nanog by porcine umbilical cord (PUC) matrix cells. Reprod Biol Endrocrinol 4:8

Corradetti B, Lange-Consiglio A, Cremonesi F, Bizzaro D (2008) Isolation, in vitro culture and characterization of foetal umbilical cord stem cells at birth. Vet Res Commun 32:139-142

Corradetti B, Meuci A, Bizzaro D, Cremonesi F, Lange-Consiglio A (2013) Mesenchymal stem cells from amnion and amniotic fluid in the bovine. Reproduction 145:391-400

Corrao S, La Rocca G, Lo Iacono M, Corsello T, Farina F, Anzalone R (2013) Umbilical cord revisited: from Wharton's jelly to mesenchymal stem cells. Histol Histopathol 28:1235-1244

Cortes Y, Ojeda M, Araya D, Dueñas F, Fernández MS, Peralta OA (2013) Isolation and multilineage differentiation of bone barrow mesenchymal stem cells from abattoir-derived bovine fetuses. BMC Vet Res 9:133

Cremonesi F, Violini S, Lange-Consiglio A, Ramelli P, Ranzenigo G, Mariani P (2008) Isolation, in vitro culture and characterization of foal umbilical cord stem cells at birth. Vet Res Commun 32:139-142

Cremonesi F, Corradetti B, Lange-Consiglio A (2011) Fetal adnexa derived stem cells from domestic animal: progress and perspectives. Theriogenology 75:1400-1415

De Miguel MP, Fuentes-Julián S, Blázquez-Martinez A, Pascual CY, Aller MA, Arias J, Arnalich-Montiel F (2012) Immunosuppressive properties of mesenchymal stem cells: advances and applications. Curr Mol Med 12:574-591

Dominici M, Le Blanc K, Mueller I, Slaper-Cortenbach I, Marini F, Krause D, Deans R, Keating A, Prockop DJ, Horwitz E (2008) Minimal criteria for defining multipotent mesenchymal stromal cells. The International Society for cellular therapy position statement. Cytotherapy 8:315-317

Godoy RF, Alves ALG, Gibson AJ, Lima EMM, Goodship AE (2014) Do progenitor cells from different tissue have the same phenotype? Res Vet Sci 96:454-459

Gottipamula S, Muttigi MS, Kolkundkar U, Seetharam RN (2013) Serum free media for the production of human mesenchymal stromal cells: a review. PLOS ONE 8:e74478

Iacono E, Merlo B (2015) Stem cells from foetal adnexa and fluid in domestic animals: an update on their features and clinical application. Reprod Domest Anim 50:353-364

Lu T, Huang Y, Wang H, Ma Y, Guan W (2011) Multi-lineage potential research of bone marrow-derived stromal cells (BMSCs) from cattle. Appl Biochem Biotechnol 72:21-35

Mukonoweshuro B, Brown CJF, Fisher J, Ingham E (2014) Immunogenicity of undifferentiated and differentiated allogenic mouse mesenchymal stem cells. J Tissue Eng 5:1-15 
Oda Y, Tani K, Kanei T, Haraguchi T, Itamoto K, Nakazawa H, Taura Y (2013) Characterization of neuron-like cells derived from canine bone marrow stromal cells. Vet Res Commun 37:133-138

Pham PV, Truong NC, Le P T-B, Tran T D-X, Vu NB, Bui K H-T, Phan NK (2016) Isolation and proliferation of umbilical cord tissue derived mesenchymal stem cells for clinical applications. Cell Tissue Bank 72:289-302

Poncelet AJ, Vercruysse J, Saliez A, Giandlo P (2007) Although pig allogenic mesenchymal stem cells are not immunogenic in vivo, intracardiac injection elicits an immune response in vivo. Transplantation 83:783-790

Prasanna SJ, Gopalakrishnan D, Shankar RS, Vasandan AB (2010) Proinflammatory cytokines, IFN $\gamma$ and TNF $\alpha$, influence immune properties of human bone marrow and Wharton jelly mesenchymal stem cells differentially. PLoS ONE 5:e9016

Raoufi MF, Tajik P, Dehghan MM, Eini F, Barin A (2011) Isolation and differentiation of mesenchymal stem cells from bovine umbilical cord blood. Reprod Domest Anim 46:95-99

Silva CG, Martins CF, Cardoso TC, Cunha ER, Bessler HC, Martins GHL, Pivato I, Báo SN (2016) Production of bovine embryos and calves cloned by nuclear transfer using mesenchymal stem cells from amniotic fluid and adipose tissue. Cell Reprogram 18:127-136

Singh J, Mann A, Kumar D, Duban JS, Yadar PS (2013) Cultured buffalo umbilical cord matrix cells exhibit characteristics of multipotent mesenchymal stem cells. In Vitro Cell Dev Biol Anim 49:408-416
Somal A, Bhat IA, Pudey S, Pauda BS, Thakur N, Sarkar M, Chaudra V, Saikumar G, Sharma GT (2016) A comparative study of growth kinetics, in vitro differentiation potential and molecular characterization of fetal adnexa derived caprine mesenchymal stem cells. PLoS ONE 11:e015681

Taghizadeh RR, Cetrulo KJ, Cetrulo CL (2011) Wharton's jelly stem cells: future clinical applications. Placenta 32:5311-5315

Troyer DL, Weiss ML (2008) Concise review: Wharton's jellyderived cells are primitive stromal cell population. Stem Cells 26:591-599

Uranio MF, Valentini L, Lange-Consiglio A, Caira M, Guaricci AC, Lábbate A, Catachio CR, Ventura M, Cremonesi F, Del Aquila ME (2011) Isolation, proliferation, cytogenetic, and molecular characterization and in vitro differentiation potency of canine stem cells from foetal adnexa: a comparative study of amniotic fluid, amnion, and umbilical cord matrix. Mol Reprod Dev 78:361-373

Weiss ML, Anderson C, Medicetty S, Seshareddy KB, Weiss RJ, VanderWerff I, Troyer D, McIntosh KR (2008) Immune properties of human umbilical cord Wharton's jelly-derived cells. Stem Cells 26:2865-2874

Yang C, Madhu V, Thomas C, Yang X, Du X, Dighe A, Cui Q (2015) Inhibition of differentiation and function of osteoclasts by dimethyl sulfoxide (DMSO). Cell Tissue Res 362:577-585 